\title{
ETHICAL GUIDELINES FOR \\ EDUCATIONAL DEVELOPERS
}

\section{Preamble}

As professionals, educational developers (faculty, teaching assistant, organizational, instructional, and staff developers) have a unique opportunity and a special responsibility to contribute to the improvement of the quality of teaching and learning in higher education. As members of the academic community, they are subject to all the codes of conduct and ethical guidelines that already exist for those who work or study on campuses and those who belong to disciplinary associations. Educational developers have special ethical responsibilities because of the unique and privileged access they have to people and often to sensitive information. This document provides general guidelines to inform the practice of professionals working in educational development roles in higher education.

Educational developers in higher education come from various disciplinary areas and follow different career tracks. Some work as educational developers on a part-time basis or for simply a short time, but for others, educational development is a full-time career. The nature of their responsibilities and prerogatives as developers varies with their position in the organization, their experience, interests, and talents, and the special characteristics of their institutions. This document attempts to provide general ethical guidelines that should apply to most developers across a variety of settings.

Ethical guidelines indicate a consensus among practitioners about the ideals that should inform their practice as professionals, as well as those behaviors that would constitute misconduct. Between the ideal of exemplary practice and misconduct lies a gray area where dilemmas arise: choices may seem equally right or wrong; different roles and responsibilities may place competing, if not incompatible, demands on developers; or certain behaviors may seem questionable but no consensus can determine that those behaviors are examples of misconduct.

It is our hope that these guidelines complement typical programmatic statements of philosophy and mission and that educational developers 
can use the guidelines effectively to promote ethical practice. This document describes the ideals of practice, identifies specific behaviors that typify professional misconduct, and provides a model to think through situations that present conflicting choices or questionable behavior.

\section{Guidelines for Practice}

\section{Ideals of Practice}

Ideals that should inform the practice of educational developers include the following areas of professional behavior: providing responsible service to clients, demonstrating competence and integrity, ensuring that the rights of others are respected, maintaining the confidentiality of any information regarding contact with clients, and fulfilling responsibilities to the profession of educational development as a whole. It is expected that educational developers will understand and integrate these ideals into their daily practice. Even though the following categories are viewed as ideals of practice, many of the individual statements are quite concrete and practical, while others encourage educational developers to attain a high standard of excellence.

Educational developers evince a high level of responsibility to their clients and are expected to:

1. Provide services to everyone within their mandate, provided that they are able to serve all clients responsibly

2. Treat clients fairly, respecting their uniqueness, their fundamental rights, dignity and worth, and their right to set objectives and make decisions

3. Maintain appropriate boundaries in the relationship, avoid exploiting the relationship in any way, and be clear with themselves and their clients about their specific role

4. Protect all privileged information, obtaining informed consent from clients before using or referring publicly to client cases in such a way that the client could be identified

5. Continue service only as long as the client is benefiting, discontinue service by mutual consent, and suggest other resources to meet needs they cannot or should not address

\section{Competence and Integrity}

Aspects of competence and integrity discussed in these guidelines include the behavior of educational developers, the skills and the boundaries they 
should respect and enforce, and the need for them to ensure the rights of their clients. Educational developers should also interact competently and with integrity in relationships with their coworkers, supervisees, and the community.

BEHAVIOR. In order to ensure evidence of competence and integrity, educational developers should:

a. Clarify professional roles and obligations

b. Accept appropriate responsibility for their behavior

c. Make no false or intentionally misleading statements

d. Avoid the distortion and misuse of their work

e. Clarify their roles and responsibilities with each party from the outset when providing services at the behest of a third party

f. Accept appropriate responsibility for the behavior of those they supervise

g. Model ethical behavior with coworkers and those they supervise and in the larger academic community

SKILLS AND BOUNDARIES. To practice effectively, educational developers need an awareness of their belief systems, personal skills, and personal knowledge base and cognizance of their own and their clients' boundaries. Ethical practice requires that educational developers:

a. Be reflective and self-critical in their practice

b. Seek out knowledge, skills, and resources continually to undergird and expand their practice

c. Consult with other professionals when they lack the experience or training for a particular case or endeavor or if they seek to prevent or avoid unethical conduct

d. Know and work within the boundaries of their competence and time limitations

e. Know and act in consonance with their purpose, mandate, and philosophy, integrating the latter insofar as possible

f. Strive to be aware of their own belief systems, values, biases, needs, and the effect of these on their work

g. Incorporate diverse points of view

h. Allow no personal or private interests to conflict or appear to conflict with professional duties or clients' needs 
i. Take care of their personal welfare so they can facilitate clients' development

j. Ensure that they have the institutional freedom to do their job ethically

CLIENTS' RIGHTS. Because educational developers work in a variety of settings with a variety of clients and interact within different teaching and learning contexts, they must be sensitive to and respectful of intellectual, individual, and power differences. Educational developers should thus:

a. Be receptive to different styles and approaches to teaching and learning and to others' professional roles and functions

b. Respect the rights of others to hold values, attitudes, and opinions different from their own

c. Respect the right of clients to refuse services or to request the services of another professional

d. Work against harassment and discrimination of any kind, including race, ethnicity, gender, class, religion, sexual orientation, disability, age, nationality, etc.

e. Be aware of various power relationships with clients (e.g., power based on position or on information) and not abuse their power.

\section{Confidentiality}

Educational developers maintain confidentiality regarding client identity, information, and records within appropriate limits and according to legal regulations. Educational developers should:

a. Keep confidential the identity of clients, as well as their professional observations, interactions, or conclusions related to specific clients or cases

b. Know the legal requirements regarding appropriate and inappropriate professional confidentiality (e.g., for cases of murder, suicide, or gross misconduct)

c. Store and dispose of records in a safe way; and comply with institutional, state, and federal regulations about storing and ownership of records

d. Conduct discreet conversations among professional colleagues in supervisory relationships and never discuss clients in public places 


\section{Responsibilities to the Profession}

Educational developers work with colleagues in the local, national, and international arena. In order to ensure the integrity of the profession, they:

a. Attribute materials and ideas to their creators or authors

b. Contribute ideas, experience, and knowledge to colleagues

c. Respond promptly to requests from colleagues

d. Respect colleagues and acknowledge collegial differences

e. Work positively for the development of individuals and the profession

f. Cooperate with other units and professionals involved in development efforts

g. Are advocates for their institutional and professional missions

\section{Professional Misconduct}

The professional misconduct of educational developers would reflect gross negligence and disdain for the Guidelines for Practice stated above. Unethical, unprofessional, and incompetent behaviors carried out by educational developers should be brought to the attention of the association. Individual educational developers should take responsibility if or when they become aware of gross unethical conduct by any colleague in the profession.

\section{Ethical Conflicts in Educational Development}

CONFLICTS ARISING FROM MULTIPLE RESPONSIBILITIES, CONSTITUENTS, RELATIONSHIPS, AND LOYALTIES. Educational developers may encounter conflicts that arise from multiple responsibilities, constituents, relationships, and loyalties. Because educational developers are responsible to their institutions, faculty, graduate students, undergraduate students, and themselves, it is inevitable that conflict will arise. For example, multiple responsibilities and relationships to various constituencies, together with competing loyalties, may lead to conflicting ethical responsibilities. The following examples point out situations in which conflicts may arise and identify the specific conflict:

Example 1: An instructor is teaching extremely poorly, and students in the class are suffering seriously as a result. Conflict: In this 
situation, the educational developer is faced with a conflict between the responsibility of confidentiality to the client-teacher and responsibility to the students and the institution.

Example 2: A faculty member wants to know how a teaching assistant with whom the educational developer is working is progressing in his or her consultation or in the classroom. Conflict: In this situation, the educational developer is faced with a conflict between responding to the faculty member's legitimate concern and with maintaining confidentiality vis-à-vis the teaching assistant.

Example 3: The educational developer knows firsthand that a professor-client is making racist or sexist remarks or is sexually harassing a student. Conflict: In this situation, the educational developer is faced with a conflict between confidentiality vis-à-vis the professorclient and not only institutional and personal ethical responsibilities but responsibility to the students as well.

Example 4: A fine teacher who has worked with the educational developer for two years is coming up for tenure and asks that a letter be written to the tenure committee. Conflict: In this situation, the educational developer is faced with a conflict between rules regarding client confidentiality and the educational developer's commitment to advocate for good teaching on campus and in tenure decisions.

In such instances of conflict, educational developers need to practice sensitive and sensible confidentiality. It is best that they:

1. Consult in confidence with other professionals when they are faced with conflicting or confusing ethical choices.

2. Inform the other person or persons when they have to break confidentiality, unless doing so would jeopardize their personal safety or the safety of someone else.

3. Break confidentiality according to legal precedent in cases of potential suicide, murder, or gross misconduct. In such cases, to do nothing is to do something.

4. Decide cases of questionable practice individually, after first informing themselves to the best of their ability of all the ramifications of their actions.

5 . Work to determine when they will act or not act, while being mindful of the rules and regulations of the institution and the relevant legal requirements. 
CONFLICTS ARISING FROM MULTIPLE ROLES. Educational developers often assume or are assigned roles that might be characterized as teaching police, doctor, coach, teacher, or advocate, among others. They are expected to be institutional models or even the conscience for good teaching on their campuses. Yet in their work with professors and graduate students, they endeavor to provide a safe place for their clients to work on their teaching. Another potential area for conflict arises from the fact that educational developers may serve as both faculty developers and as faculty members. As developers, they support clients in their efforts to improve their teaching; in their role as faculty, they often serve on review committees that evaluate other faculty. Either role may give them access to information that cannot appropriately be shared or communicated beyond the committee or the consultation relationship (even if it would be useful for the other role).

An important area of potential conflict exists in the case of the summative evaluation of teaching. Departmental faculty and campus administrators (chairs, deans, etc.) are responsible for the assessment of teaching for personnel decisions. Educational developers should not generally be placed in this situation because of the confidentiality requirements noted in the section on Guidelines for Practice. In general, educational developers do not make summative judgments about an individual's teaching. In particular, they should never perform the role of developer and summative evaluator concurrently for the same individual unless they have that person's explicit consent and with proper declaration to any panel or committee involved. However, educational developers may:

1. Provide assessment tools

2. Collect student evaluations

3. Help individuals prepare dossiers

4. Educate those who make summative decisions

5. Critique evaluation systems

\section{Conclusion}

This document is an attempt to define ethical behaviors for the current practice of educational development in higher education. In creating this document the POD Network has referred to and borrowed from the Ethical Guidelines of the American Psychological Association, the American Association for Marriage and Family Therapy, Guidance 
Counselors, the Society for Teaching and Learning in Higher Education in Canada, and the Staff and Educational Development Association in the United Kingdom. The association will continue to refine these guidelines in light of the changes and issues that confront the profession. The guidelines will be updated on a periodic basis by the Core Committee of the Professional and Organizational Development Network in Higher Education. 